\title{
Silencing of death receptor and caspase-8 expression in small cell lung carcinoma cell lines and tumors by DNA methylation
}

\author{
S Hopkins-Donaldson* ${ }^{\star 1}$, A Ziegler ${ }^{1}$, S Kurtz ${ }^{1}$, C Bigosch ${ }^{1}$, \\ D Kandioler $^{2}$, C Ludwig ${ }^{2}$, U Zangemeister-Wittke ${ }^{1}$ and R Stahel ${ }^{2}$ \\ 1 Division of Oncology, University Hospital Zürich, Zürich 8044, Switzerland \\ 2 Department of Surgery, University of Vienna Medical School, 1090 Vienna, \\ Austria \\ * Corresponding author: S Donaldson, Division of Oncology, Häldeliweg 4, \\ UniversitätsSpital Zürich, Zürich 8044, Switzerland. Tel: 41634 2874; \\ Fax: 41634 2872; E-mail: Sally.Donaldson@dim.usz.ch
}

Received 5.4.02; revised 24.9.02; accepted 26.9.02

Edited by SJ Martin

\begin{abstract}
Small cell lung cancer cell lines were resistant to FasL and TRAIL-induced apoptosis, which could be explained by an absence of Fas and TRAIL-R1 mRNA expression and a deficiency of surface TRAIL-R2 protein. In addition, caspase-8 expression was absent, whereas FADD, FLIP and caspases-3, $-7,-9$ and -10 could be detected. Analysis of SCLC tumors revealed reduced levels of Fas, TRAIL-R1 and caspase-8 mRNA compared to non-small cell lung cancer (NSCLC) tumors. Methylation-specific PCR demonstrated methylation of CpG islands of the Fas, TRAIL-R1 and caspase- 8 genes in SCLC cell lines and tumor samples, whereas NSCLC samples were not methylated. Cotreatment of SCLC cells with the demethylating agent 5 -aza-2-deoxycytidine and IFN $\gamma$ partially restored Fas, TRAIL-R1 and caspase-8 expression and increased sensitivity to FasL and TRAIL-induced death. These results suggest that SCLC cells are highly resistant to apoptosis mediated by death receptors and that this resistance can be reduced by a combination of demethylation and treatment with IFN $\gamma$.

Cell Death and Differentiation (2003) 10, 356-364. doi:10.1038/ sj.cdd. 4401157
\end{abstract}

Keywords: caspase-8; Fas; TRAIL; SCLC; DNA methylation

Abbreviations: SCLC, small cell lung cancer; MSP, methylation-specific PCR; 5-AzaC, 5'-aza-2-deoxycytidine; IFN $\gamma$, interferon gamma

\section{Introduction}

Lung cancer is the second most common cause of death after cardiovascular disease and is the major cause of cancer deaths in the Western world. ${ }^{1}$ Small cell lung carcinoma (SCLC) is a neuroectoderm-derived tumor that originates from neuroendocrine cells of the bronchoepithelium. ${ }^{2}$ and accounts for $25 \%$ of lung cancers. It represents a particularly aggressive form of the disease, characterized by early and widespread metastases. Although initially responsive to chemotherapy, SCLC has only a 5\% 5-year survival rate due to recurrent tumors. SCLC shares phenotypic similarities with the pediatric cancer neuroblastoma, including the amplification of the $\mathrm{N}-m y c$ oncogene, which correlates with poor prognosis in both diseases.,

Impaired apoptosis has been recognized as a major contributor to tumor development and drug resistance. ${ }^{5}$ In mammalian cells, apoptosis is induced by two distinct pathways. The mitochondrial pathway is triggered by DNA damage and involves the release of cytochrome $c$ from mitochondria and the subsequent activation of caspase- 9 and downstream effector caspases-3, -6 and -7 . In contrast, the death receptor pathway is induced by ligands of the tumor necrosis factor (TNF) family such as FasL/CD95L and TRAIL (TNF-related apoptosis-inducing ligand)/APO2L, which signal apoptosis by binding to the cell surface receptors Fas/CD95, and TRAIL-R1/DR4 and TRAIL-R2/DR5 respectively. ${ }^{6}$ On binding ligand, the receptors dimerize and form a cytosolic complex with the adaptor protein FADD/MORT, which recruits procaspase- 8 and/or procaspase-10, resulting in their activation and the cleavage of the effector caspases. In some instances, caspase-8 also cleaves Bid, which amplifies the death receptor signal by inducing mitochondrial cytochrome $c$ release and caspase- 9 activation. ${ }^{7}$

Up to $90 \%$ of SCLC tumors and cell lines overexpress the antiapoptotic molecule $\mathrm{Bcl}-2$ which negatively regulates the mitochondrial pathway by blocking cytochrome $c$ release. ${ }^{8,9}$ There is also evidence suggesting that impairment of the death receptor pathway in SCLC might be an additional mechanism involved in the resistance of SCLC cells to apoptosis. Studies on SCLC cell lines revealed that, in some cases, missense point mutations occur in the TRAIL-R1 gene, ${ }^{10}$ and in addition the expression of caspases- 8 and -10 is often absent. ${ }^{11}$ However, these studies did not assess the sensitivity of SCLC cells to the death receptor pathway, and SCLC tumor samples were not examined. In this study, we were interested in determining whether SCLC cells were indeed resistant to the death receptor pathway and, if so, to identify the mechanisms responsible. We found that SCLC cells are resistant to FasL and TRAIL-induced death, and demonstrate that DNA methylation is responsible for the silencing of Fas, TRAIL-R1 and caspase-8 expression.

\section{Results}

\section{Resistance of SCLC cells to FasL and TRAIL-induced apoptosis}

The sensitivity of SCLC cells to the death receptor pathway was first investigated by treating cell lines with the ligands 
FasL and TRAIL. Cells were incubated for $16 \mathrm{~h}$ with supernatant derived from Neuro2A cells expressing FasL or with crosslinked recombinant TRAIL, and MTT cell viability and trypan blue cell death assays were performed (Figure 1a, b). At the concentration of ligands used, Jurkat $T$ cells were highly sensitive to both FasL and TRAIL, whereas the non-small cell lung carcinoma (NSCLC) cell line H460 was only moderately sensitive and all SCLC cell lines tested were completely resistant. Caspase-3-like activity could be detected in both Jurkat T cells and $\mathrm{H} 460$ cells after $4 \mathrm{~h}$ incubation with FasL or
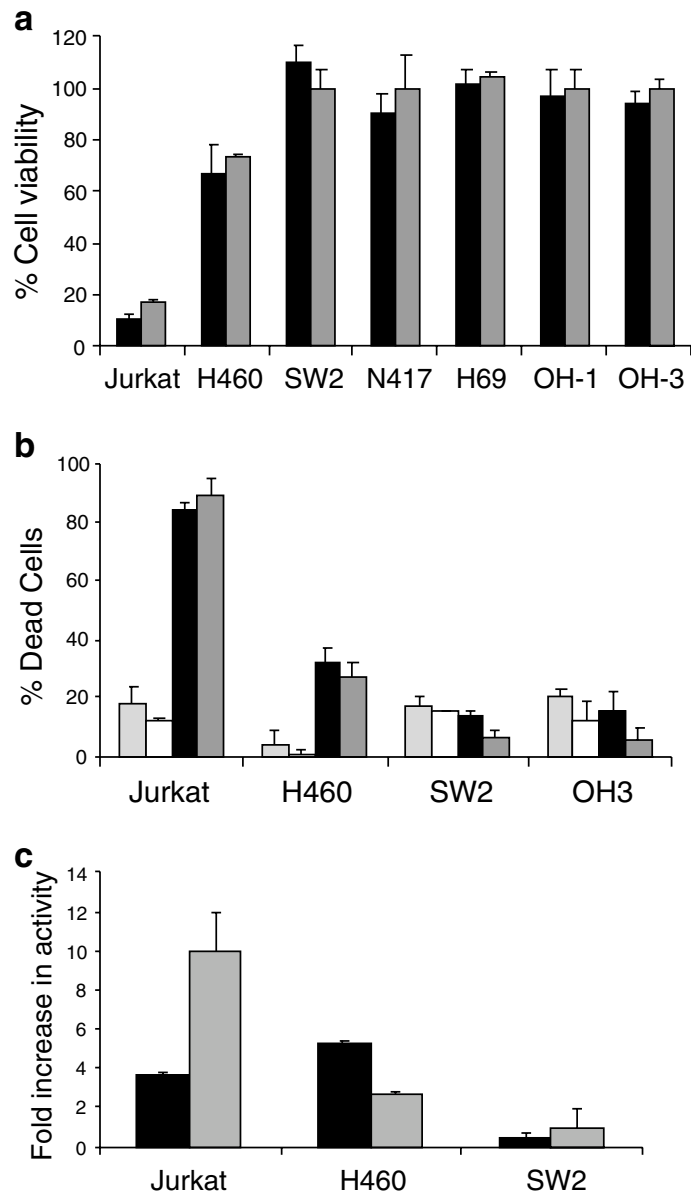

Figure 1 Resistance of SCLC cells to FasL and TRAIL-induced apoptosis. (a) The MTT assay was used to measure decreased cell growth induced by FasL and TRAIL. Cells were incubated for $16 \mathrm{~h}$ with $10 \%$ FasL supernatant (black columns) or with $100 \mathrm{ng} / \mathrm{ml}$ crosslinked TRAIL (gray columns), $10 \%$ control supernatant or medium alone. Assays were performed in quadruplicate, and the mean percentage cell viability of FasL- and TRAIL-treated cells was calculated compared to cells treated with control supernatant or untreated cells, respectively. Error bars represent the S.D. of replicate wells. (b) Cell death induced by FasL and TRAIL was measured by trypan blue staining. Cells were incubated for $16 \mathrm{~h}$ with medium alone (pale-gray columns), $10 \%$ control supernatant (white columns), 10\% FasL-containing supernatant (black columns) or with $100 \mathrm{ng} / \mathrm{ml}$ crosslinked TRAIL (dark-gray columns). The percentage of dead cells in each sample was determined after trypan blue staining. Samples were measured in triplicate and mean +S.D. values calculated. (c) Measurement of caspase-3-like activity. Cells were treated for $4 \mathrm{~h}$ with $10 \%$ supernatant containing FasL (black columns) or $100 \mathrm{ng} / \mathrm{ml}$ crosslinked TRAIL (gray columns). The fold increase in activity induced by FasL or TRAIL was calculated compared to values obtained from cells incubated with $10 \%$ control supernatant or medium, respectively. The mean+S.D. of three independent experiments are shown
TRAIL; however no activity was measured for the SCLC cell line SW2 (Figure 1c).

\section{Expression of death receptors in SCLC cells and tumors}

In order to determine why SCLC cell lines were resistant to the death receptor pathway, FACs analysis was performed to measure the expression of death receptors by SCLC cell lines. Figure 2 shows that intact $\mathrm{H} 460$ NSCLC cells expressed detectable amounts of surface Fas and TRAIL-R1 and R2. In contrast, no surface death receptors could be detected on SCLC cell lines SW2 and N417, nor on any of the other SCLC cell lines tested (data not shown). TRAIL receptors have been reported to be expressed intracellularly in addition to being present on the cell surface, with TRAIL-R1 and -R2 localizing to the trans-Golgi network. ${ }^{12}$ It was therefore investigated whether death receptors were located intracellularly in SCLC cells by permeabilizing them with saponin prior to FACs staining. The levels of TRAIL-R1 and TRAIL-R2-associated fluorescence were increased in $\mathrm{H} 460$ cells after permeabilization, while Fas levels remained unchanged. In permeabilized SCLC cells, the levels of TRAIL-R2 dramatically increased, whereas Fas and TRAIL-R1 could not be detected. These results suggest that TRAIL-R1 and Fas proteins are not expressed by SCLC cells and that TRAIL-R2 is retained intracellularly.

RT-PCR analysis was performed to determine whether the absence of Fas and TRAIL-R1 expression in SCLC cells was at the mRNA level. The expresssion of decoy receptors TRAIL-R3 and -R4 has been associated with resistance to TRAIL-induced death in some studies, ${ }^{12}$ therefore, the expression of TRAIL-R3 and -R4 was also investigated in SCLC by RT-PCR. H460 NSCLC cells expressed Fas and all four TRAIL death receptor mRNAs (Figure 3a). In contrast, Fas, TRAIL-R1 and -R4 mRNA were absent from all five SCLC cell lines, whereas TRAIL-R2 mRNA was detected in 3/ 5 SCLC cell lines and TRAIL-R3 mRNA was observed in all cells tested. Tumor tissue from two SCLC patients (L8 and L29) and one NSCLC patient (L20) were also investigated for their expression of death receptor mRNA (Figure $3 b$ ). In agreement with the data obtained with the $\mathrm{H} 460$ cell line, mRNA for Fas and all four TRAIL receptors was detected in the NSCLC tumor sample. In contrast, comparable to the results found with SCLC cell lines, tumor tissue from both SCLC patients contained TRAIL-R2 and-R3 mRNA, but no Fas, TRAIL-R1 or TRAIL-R4. In summary, these results demonstrate that SCLC cells do not express Fas and TRAILR1 mRNA, and although TRAIL-R2 expression does occur, the receptor was not present at the cell surface. It is therefore highly unlikely that FasL or TRAIL can signal apoptosis in these cells.

\section{Expression of intracellular members of the death receptor pathway in SCLC cell lines and tumors}

In order to determine whether further defects were present in the death receptor pathway in SCLC cells, the expression of molecules downstream of death receptors was then investi- 


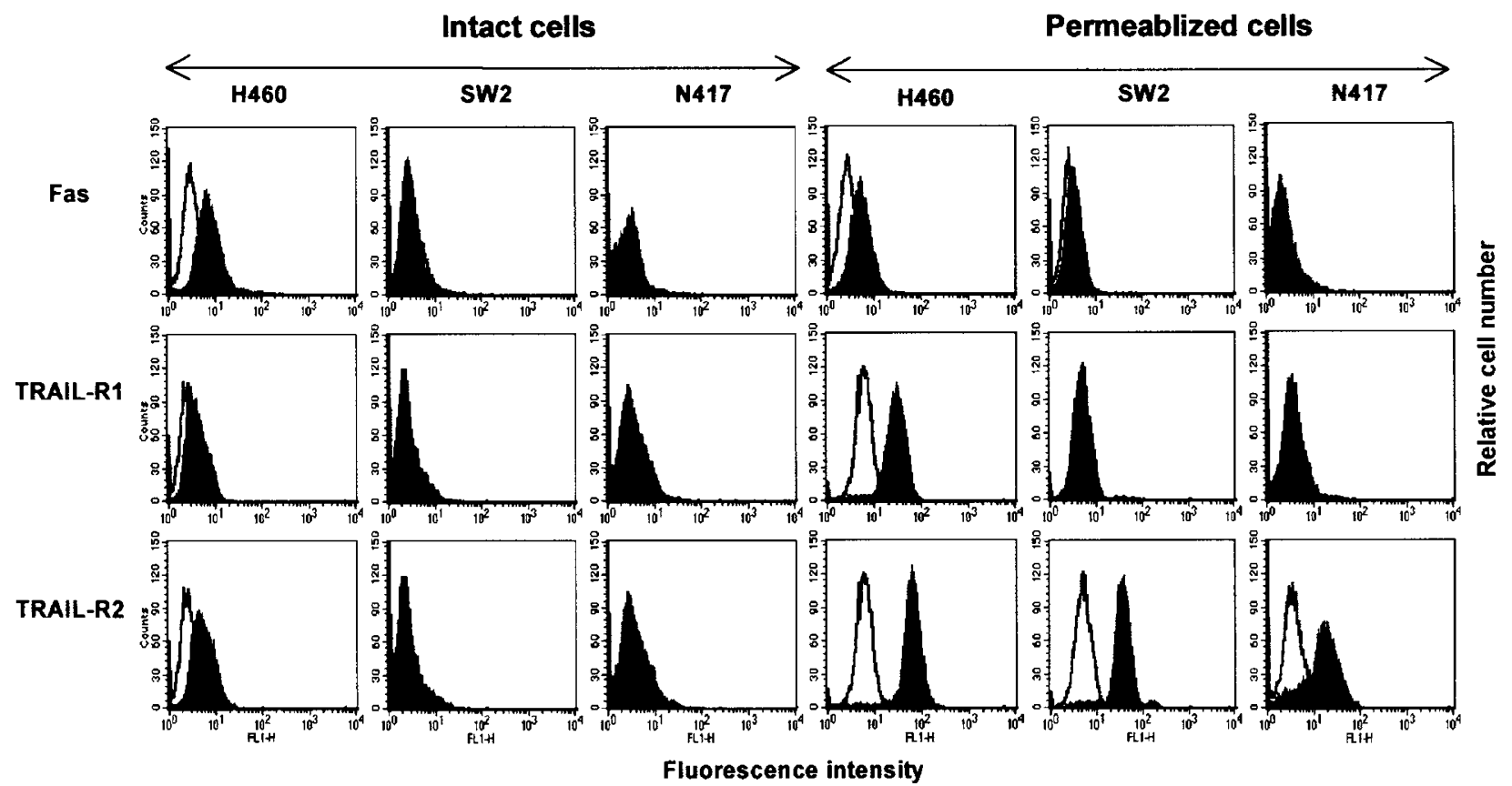

Figure 2 Measurement of death receptor expression on intact and permeabilized cells by flow cytometry. Cells were stained with anti-human Fas Mab conjugated to FITC or with TRAIL-R1 or -R2 Mabs followed by FITC-conjugated secondary antibodies (black peaks). Isotype matched controls were also included (white peaks). Permeabilized cells were treated with $0.1 \%$ saponin prior to antibody staining

a

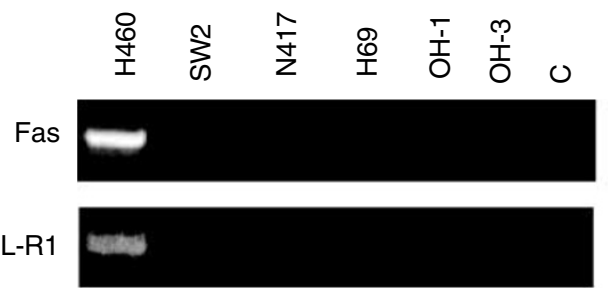

TRAIL-R2

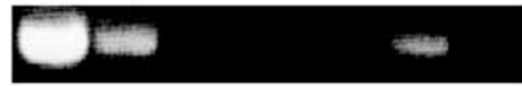

TRAIL-R3

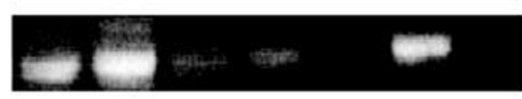

TRAIL-R4

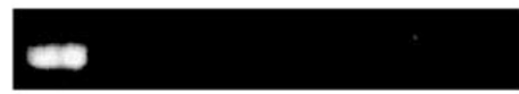

Beta actin

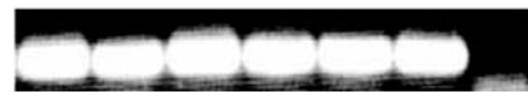

b

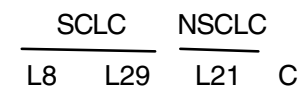

Fas

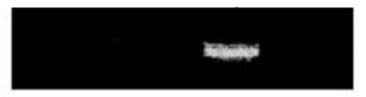

TRAIL-R1

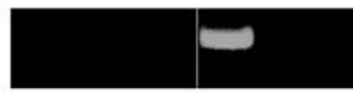

TRAIL-R2

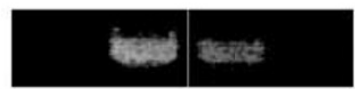

TRAIL-R3

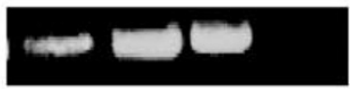

TRAIL-R4

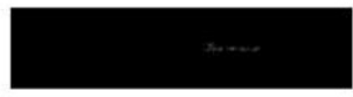

Beta actin

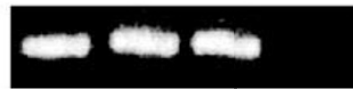

Figure 3 Detection of death receptor mRNA expression in SCLC cell lines and tumors by RT-PCR. RT-PCR was performed on RNA isolated from (a) cell lines and (b) tumor samples from 2 SCLC patients (L8 and L29) and one NSCLC patient (L20). C represents a control lane with no CDNA. One-fifth of the final PCR products were loaded on $2 \%$ agarose gels

gated by Western blotting. The adaptor molecule FADD and caspases-3, -7, -9 and -10 were detected in SCLC cells at levels comparable to Jurkat T cells (Figure 4a). In addition, the caspase-8 inhibitor FLICE inhibitory protein (FLIP) was detected in both Jurkat cells and SCLC cells. Caspase-7 was detected in the N417 cell line as a $20 \mathrm{kDa}$ fragment (data not shown), probably due to the spontaneous apoptosis that is known to occur in SCLC cells in culture. ${ }^{13}$ In contrast to other caspases, caspase-8 precursor expression was not detected in any of the SCLC cell lines, whereas it could be readily measured in Jurkat $T$ cells. To exclude the possibility that the caspase-8 precursor is cleaved and therefore not detectable in SCLC cell lines, cells were incubated with the caspase inhibitor zVADfmk prior to Western blotting; however, this did not increase the amount of caspase-8 detected (data not shown). SCLC cells were also found to be deficient for 
a

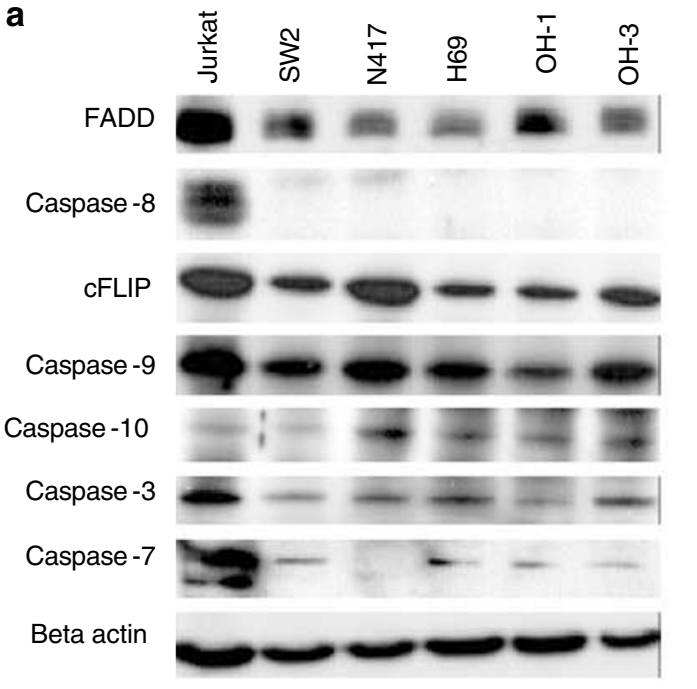

b

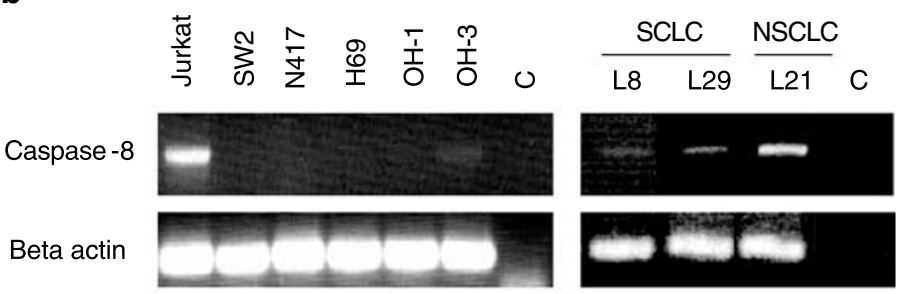

C

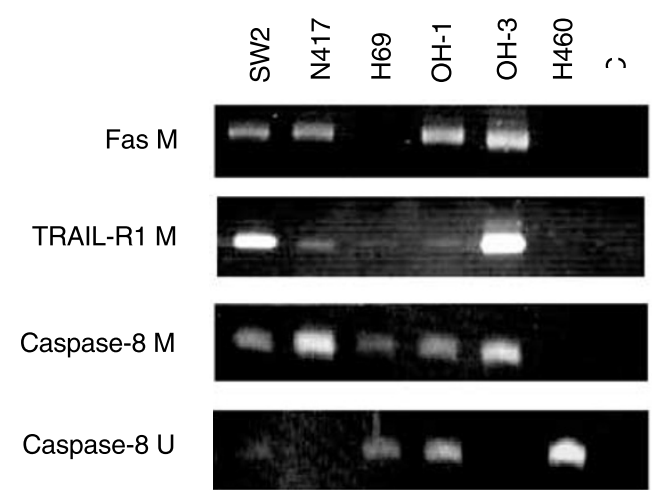

Figure 4 Detection of expression of downstream members of death receptor pathway and silencing by DNA methylation in SCLC. (a) Protein lysates (100 $\mu$ g/lane) were separated by $12 \%$ SDS-AGE and immunoblotted with antibodies specific for CFLIP, FADD and caspases-3, $-7,-8,-9,-10$ and beta actin. (b) RT-PCR was performed on RNA isolated from cell lines and tumor samples from two SCLC patients (L8 and L29) and one NSCLC patient (L20). C represents a control lane with no CDNA. One-fifth of the final PCR products were loaded on $2 \%$ agarose gels. (c) MSP to detect CpG island methylation for the Fas TRAIL-R1 and caspase-8 genes. PCR was performed on sodium bisulfite-treated DNA using primers specific for methylated $(\mathrm{M})$ or unmethylated $(\mathrm{U}) \mathrm{CpG}$ islands. One-fifth of PCR products were loaded on $6 \%$ nonreducing polyacrylamide gels; C represents a control without bisulfite-treated DNA

caspase-8 mRNA, suggesting that the inhibition of expression is at the level of transcription (Figure $4 \mathrm{~b}$ ). Caspase- 8 mRNA expression was also investigated in tumor samples derived from SCLC and NSCLC patients. Only low levels of caspase-8 mRNA were detected in samples from the two SCLC patients in comparison to the samples from the NSCLC patient, suggesting that caspase-8 expression may also be downregulated in SCLC tumors in vivo (Figure 4b).

\section{Silencing of death receptors and caspase-8 in SCLC cells}

The expression of caspase- 8 and Fas can be induced in neuroblastoma cells and ras-transformed fibroblasts respectively on treatment with the demethylating drug $5^{\prime}$-aza-2deoxycytidine (5-AzaC), indicating that both genes are silenced by DNA methylation. ${ }^{14,15}$ In order to further investigate the methylation status of the $\mathrm{CpG}$ islands present in the $5^{\prime}$ flanking regions of the caspase-8, Fas and TRAIL-R1 genes, methylation-specific PCR (MSP) was performed on sodium bisulfite-treated DNA derived from SCLC cell lines. Figure 4c shows that whereas NSCLC H460 bisulfite-treated DNA did not contain methylated caspase-8, Fas or TRAIL-R1 CpG islands, DNA from SCLC cell lines was methylated for all three CpG islands, with the exception of the H69 cell line where the Fas $\mathrm{CpG}$ island was not methylated. When primers specific for an unmethylated caspase-8 CpG island were used in MSP reactions, DNA from $\mathrm{H} 460$ cells and three out of five
SCLC cell lines were positive. This indicates that the caspase$8 \mathrm{CpG}$ island is unmethylated in $\mathrm{H} 460$ cells, and is methylated in two SCLC cell lines, whereas in the remaining three SCLC lines hemimethylation occurs due to either intercellular or interallelic heterogeneity. To further verify the MSP data, purified PCR products were digested with the restriction enzyme Taq 1, which has a CpG in its recognition sequence and can therefore distinguish between PCR products derived from methylated and unmethylated caspase-8, Fas and TRAIL-R1 samples (data not shown).

\section{Caspase-8, Fas and TRAIL-R1 CpG islands are methylated in SCLC tumors}

The methylation status of caspase-8, Fas and TRAIL-R1 CpG islands was also investigated in DNA from 25 SCLC and four NSCLC tumors (Table 1). MSP using primers specific for a methylated caspase-8 CpG island gave positive signals in $52 \%$ of SCLC samples and in none of the NSCLC samples. In contrast, MSP using primers specific for unmethylated caspase-8 CpG islands gave positive signals for all tumor samples. Taken together, this shows that the caspase-8 $\mathrm{CpG}$ island is unmethylated in NSCLC tumors and $48 \%$ of SCLC tumors, while the remaining $52 \%$ of SCLC samples were heterogeneous and contained methylated DNA and also unmethylated DNA that may have originated from contaminating nontumoral DNA. Both the Fas and TRAIL-R1 CpG islands were methylated in $40 \%$ of SCLC tumors and in none 
of the NSCLC tumors. Although only four SCLC tumors were methylated for both Fas and TRAIL-R1, 72\% of SCLC tumors were methylated for at least two of the three genes.

\section{5-AzaC and IFN $\gamma$ induce expression of silenced genes and sensitize to FasL and TRAIL-induced death}

Demethylation with 5-AzaC has been previously demonstrated to induce the expression of caspase-8 in neuroblastoma cells and to sensitize cells to TRAIL-induced apoptosis. ${ }^{14}$ In addition, IFN $\gamma$ has been recently shown to

Table 1 MSP of NSCLC and SCLC tumor DNA

\begin{tabular}{|c|c|c|c|c|c|}
\hline Tumor & Cancer & Casp-8 U & Casp-8 M & FasM & R1M \\
\hline L20 & NSCLC & $Y$ & $\mathrm{~N}$ & $\mathrm{~N}$ & $\mathrm{~N}$ \\
\hline L21 & NSCLC & $Y$ & $\mathrm{~N}$ & $\mathrm{~N}$ & $\mathrm{~N}$ \\
\hline 970 & NSCLC & $\mathrm{Y}$ & $\mathrm{N}$ & $\mathrm{N}$ & $\mathrm{N}$ \\
\hline 463 & NSCLC & $\mathrm{Y}$ & $\mathrm{N}$ & $\mathrm{N}$ & $\mathrm{N}$ \\
\hline 23 & SCLC & $\mathrm{Y}$ & $\mathrm{N}$ & $\mathrm{Y}$ & $\mathrm{Y}$ \\
\hline 185 & SCLC & $\mathrm{Y}$ & $\mathrm{N}$ & $\mathrm{N}$ & $\mathrm{N}$ \\
\hline 190 & SCLC & $\mathrm{Y}$ & $\mathrm{N}$ & $\mathrm{N}$ & $\mathrm{N}$ \\
\hline 324 & SCLC & $Y$ & $\mathrm{~N}$ & $\mathrm{~N}$ & $\mathrm{~N}$ \\
\hline 641 & SCLC & $Y$ & $\mathrm{~N}$ & $\mathrm{~N}$ & $\mathrm{~N}$ \\
\hline 696 & SCLC & $Y$ & $\mathrm{~N}$ & $\mathrm{~N}$ & $\mathrm{~N}$ \\
\hline 777 & SCLC & $\mathrm{Y}$ & $\mathrm{N}$ & $\mathrm{N}$ & $\mathrm{N}$ \\
\hline 787 & SCLC & $Y$ & $\mathrm{~N}$ & $\mathrm{~N}$ & $\mathrm{Y}$ \\
\hline $968 c$ & SCLC & $\mathrm{Y}$ & $\mathrm{N}$ & $\mathrm{N}$ & $Y$ \\
\hline $972 a$ & SCLC & $\mathrm{Y}$ & $\mathrm{N}$ & $\mathrm{N}$ & $\mathrm{Y}$ \\
\hline 106 & SCLC & $\mathrm{Y}$ & $\mathrm{N}$ & $\mathrm{Y}$ & $\mathrm{Y}$ \\
\hline 977 & SCLC & $\mathrm{Y}$ & $\mathrm{N}$ & $\mathrm{N}$ & $\mathrm{N}$ \\
\hline L8 & SCLC & $\mathrm{Y}$ & Y & $\mathrm{Y}$ & $\mathrm{Y}$ \\
\hline L29 & SCLC & $\mathrm{Y}$ & Y & $\mathrm{Y}$ & $\mathrm{Y}$ \\
\hline 5 & SCLC & $\mathrm{Y}$ & Y & $\mathrm{N}$ & $\mathrm{N}$ \\
\hline 104 & SCLC & $\mathrm{Y}$ & Y & $\mathrm{Y}$ & $\mathrm{N}$ \\
\hline 119 & SCLC & $\mathrm{Y}$ & Y & $\mathrm{Y}$ & $\mathrm{N}$ \\
\hline 152 & SCLC & $\mathrm{Y}$ & Y & Y & $\mathrm{N}$ \\
\hline 212 & SCLC & $\mathrm{Y}$ & Y & $\mathrm{N}$ & $\mathrm{Y}$ \\
\hline 241 & SCLC & $\mathrm{Y}$ & Y & $\mathrm{Y}$ & $\mathrm{N}$ \\
\hline 306 & SCLC & $\mathrm{Y}$ & Y & $\mathrm{Y}$ & $\mathrm{N}$ \\
\hline 325 & SCLC & $Y$ & $Y$ & $\mathrm{~N}$ & $\mathrm{~N}$ \\
\hline 406 & SCLC & $Y$ & $Y$ & $\mathrm{~N}$ & $\mathrm{~N}$ \\
\hline $971 a$ & SCLC & $\mathrm{Y}$ & Y & $\mathrm{N}$ & $\mathrm{Y}$ \\
\hline 149 & SCLC & $\mathrm{Y}$ & Y & $\mathrm{Y}$ & $\mathrm{Y}$ \\
\hline
\end{tabular}

Positive band in PCR: $\mathrm{Y}$, yes; N, no. upregulate caspase-8 and Fas expression in neuroblastoma cells and to sensitize them to TRAIL and FasL. ${ }^{16,17}$ Incubation of the N417 SCLC cell line with 5-AzaC and/or IFN $\gamma$ induced the expression of caspase-8, Fas and TRAIL-R1 mRNA as measured by RT-PCR (Figure 5a). Treatment with 5-AzaC and/or IFN $\gamma$ also upregulated caspase-8 protein expression as determined by Western blotting (Figure $5 b$ ), and cotreatment with both agents induced low but detectable surface Fas and TRAIL-R1 (Figure 5c) whereas levels of TRAIL-R2 were unchanged (data not shown). Coincubation of N417 cells with 5-AzaC and IFN $\gamma$ increased their sensitivity to TRAIL and FasL, while treatment with either agent alone had little effect (Figure 5d).

\section{Discussion}

Several genetic events that result in resistance to apoptosis induced by death receptors have been described in different cancer types. These include mutations in the death receptor genes ${ }^{18}$ and overexpression of inhibitory molecules such as soluble death receptors, ${ }^{19}$ decoy receptors ${ }^{20}$ and FLIP. ${ }^{21}$ In addition, epigenetic silencing of members of the death receptor pathway via DNA methylation can also occur. We and others have shown that caspase- 8 expression is silenced in neuroblastoma and primary neuroectodermal brain tumors, ${ }^{14,22}$ whereas in prostate and bladder carcinomas Fas expression is silenced. ${ }^{23}$ In the present study, SCLC cells were found to be highly resistant to the death receptor pathway induced by FasL or TRAIL. The mechanisms responsible for this resistance were found to include the silencing of Fas, TRAIL-R1 and caspase-8 genes by DNA methylation, and the intracellular retention of TRAIL-R2.

We observed that TRAIL-R2 mRNA was expressed in three out of five SCLC cell lines as well as in two SCLC tumor samples. In agreement with these findings, TRAIL-R2 mRNA expression was also previously reported in 12 out of 20 SCLC cell lines. ${ }^{24}$ Whether those cell lines that do not express TRAIL-R2 are silenced by DNA hypermethylation is currently under investigation. In cell lines that expressed TRAIL-R2, expression was observed to be intracellular, as only permeabilization of cells prior to FACs staining gave a positive signal. Similarly, Zhang et al. ${ }^{12}$ reported that TRAIL-R2 is located in the trans-Golgi network (TGN) in addition to the cell membrane in melanoma cells. ${ }^{12}$ The mechanism for the intracellular retention of TRAIL-R2 in SCLC cells remains to

Table 2 Primer sequences used for MSP

\begin{tabular}{ll}
\hline Primer & \multicolumn{1}{c}{ Sequence } \\
\hline Casp-8 methylated forward & TAGGGGATTCGGAGATTGCGA \\
Casp-8 methylated reverse & CGTATATCTACATTCGAAACGA \\
Casp-8 unmethylated forward & TAGGGGATTTGGAGATTGTGA \\
Casp-8 unmethylated reverse & CCATATATCTACATTCAAAACAA \\
Fas methylated forward & AGAAAGGGTAGGAGGTCG \\
Fas methylated reverse & ATCACTCTTACGCGAAATC \\
TRAIL-R1 methylated forward & GAGCGTAGCGAGTGGGATAGAG \\
TRAIL-R1 methylated Reverse & CCGAACCCGAACACTAAATCCG
\end{tabular}


a

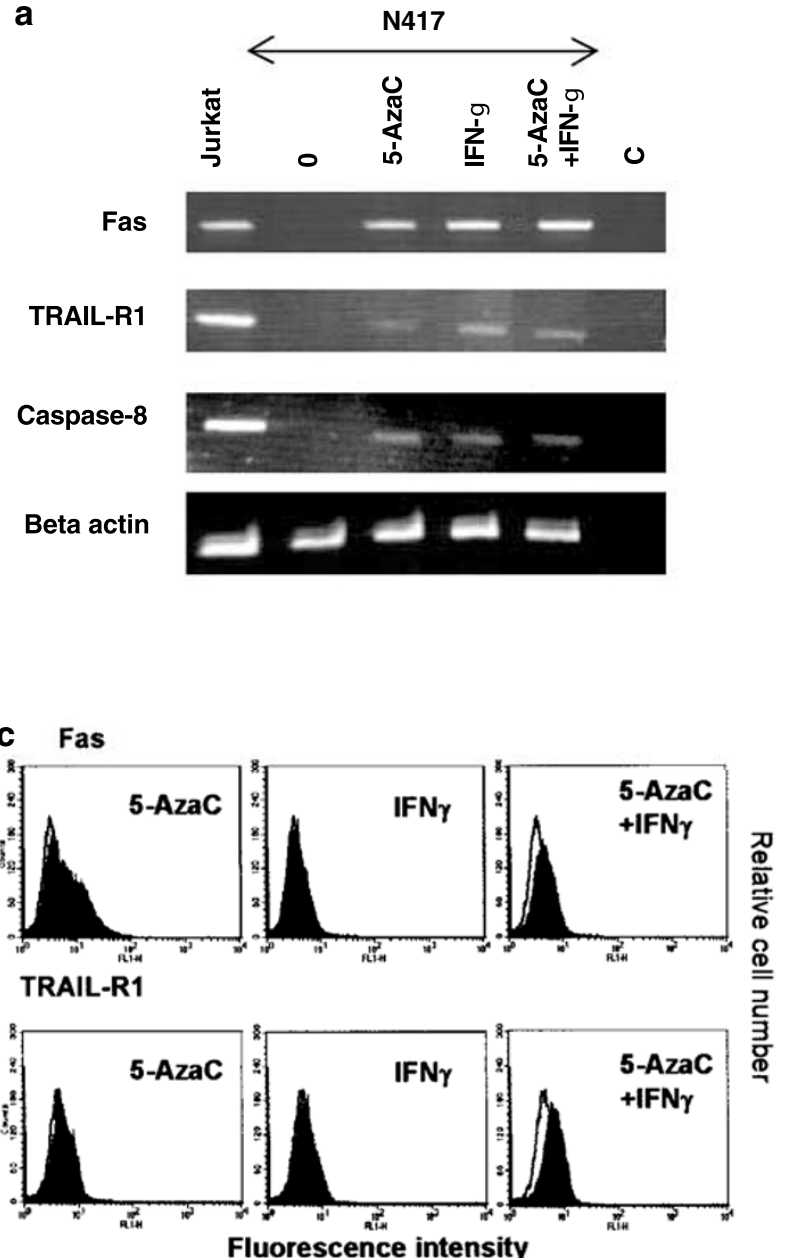

b

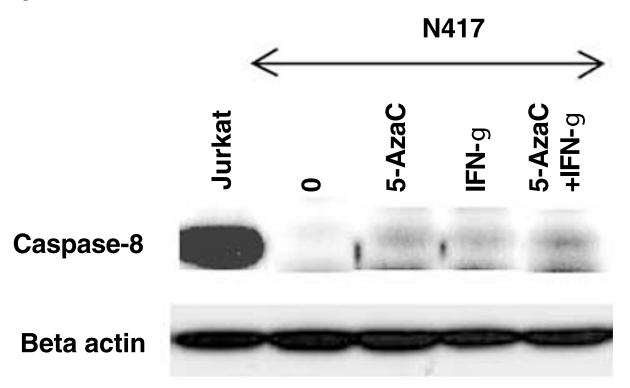

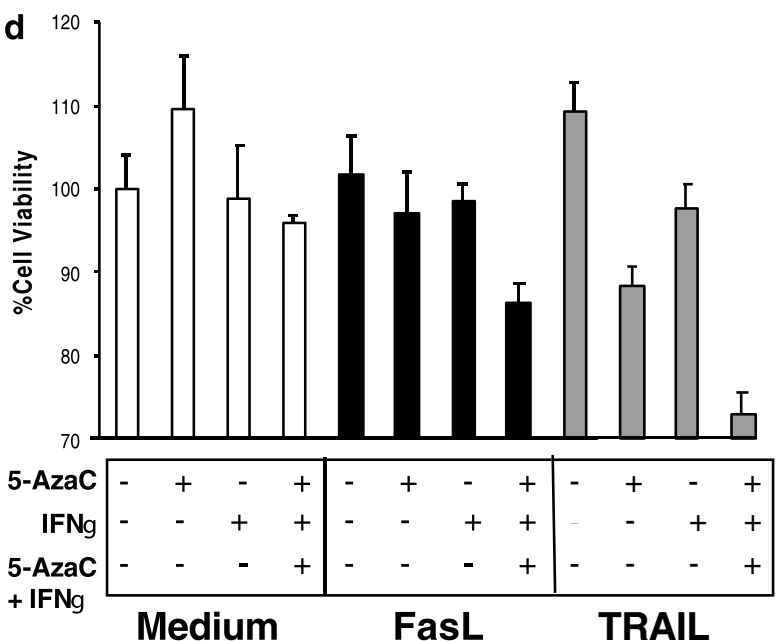

Figure 5 Incubation with 5-AzaC and IFN $\gamma$ induces caspase-8, Fas and TRAIL-R1 expression in SCLC cells and sensitizes them to death-receptor-mediated apoptosis. (a) RT-PCR was performed on RNA isolated from Jurkat T cells or N417 cells treated with $1 \mu \mathrm{M}$ 5-AzaC and/or $2500 \mathrm{U} / \mathrm{ml} \mathrm{IFN} \gamma$ for $72 \mathrm{~h}$. Primers specific for Fas, TRAIL-R1, caspase- 8 or beta actin were used to amplify cDNA and one-fifth of PCR products were loaded on $2 \%$ agarose gels. $C$ represents a control PCR reaction without cDNA. (b) Western blotting was performed on Jurkat T cells or N417 cells treated with $1 \mu \mathrm{M} 5$-AzaC and/or $2500 \mathrm{U} / \mathrm{ml} \mathrm{IFN} \gamma$ for $72 \mathrm{~h}$. Protein lysates (100 $\mu \mathrm{g} / \mathrm{lane}$ ) were separated by $12 \%$ SDS-PAGE and immunoblotted with mouse Mabs specific for caspase-8 and beta actin. (c) Measurement of death receptor expression in N417 cells after $72 \mathrm{~h}$ incubation with $1 \mu \mathrm{M} 5-\mathrm{AzaC}$ and/or $2500 \mathrm{U} / \mathrm{ml} \mathrm{IFN} \gamma$ by flow cytometry. Cells were stained with anti-human Fas Mab conjugated to FITC or with TRAIL-R1 Mabs followed by FITC-conjugated secondary antibodies (black peaks). Isotype matched controls were also included (white peaks). (d) Cells were incubated for $72 \mathrm{~h}$ with medium (white columns), $10 \%$ FasL supernatant (black columns) or $200 \mathrm{ng} / \mathrm{ml}$ crosslinked TRAIL (gray columns) either alone or in combination with $1 \mu \mathrm{M} 5$-AzaC and/or $2500 \mathrm{U} / \mathrm{ml} \mathrm{IFN} \gamma$. Assays were performed in quadruplicate, and the mean percentage cell viability of FasL- and TRAIL-treated cells was calculated compared to cells treated with control supernatant or untreated cells, respectively. Error bars represent the S.D. of replicate wells

be elucidated; however, the finding that the TRAIL-R3 decoy receptor is expressed by all SCLC cells and tumors suggests that it may be involved.

Although the inhibitory molecule FLIP was expressed by all SCLC cell lines tested, its importance in TRAIL resistance remains questionable, since TRAIL-sensitive Jurkat $T$ cells expressed similar levels of this molecule. In addition, the FLIP molecule is thought to inhibit death-receptor-induced apoptosis by competing with caspase- 8 for the death receptor complex. ${ }^{21}$ The absence of caspase-8 expression in SCLC cells would therefore make the function of FLIP redundant. An alternative role for FLIP has been proposed whereby it activates NF-kappa B, resulting in increased cell survival. ${ }^{25}$ The expression of FLIP by SCLC cells may therefore be important for cell survival even in the absence of caspase-8.
CpG 'islands' occur in the promoter regions of almost half of the genes of the human genome and are usually unmethylated. However, in cancer cells, methylation of $\mathrm{CpG}$ islands occurs more frequently and correlates with transcriptional repression. The silencing of tumor suppressor gene expression in this manner is thought to contribute to carcinogenesis. ${ }^{26}$ Mutations in the caspase-8, ${ }^{27}$ Fas $^{28}$ and TRAIL-R $1^{10}$ genes have been detected in cancer cells, suggesting that they may be tumor suppressor genes that are inactivated by either DNA methylation or mutation as part of the malignant process. Although silencing of caspase-8 expression by DNA methylation has been previously described in pediatric cancers, the present study is the first to show that a similar phenomenon occurs in an adult cancer of much higher incidence. The silencing of tumour suppressor genes is often 
an early event in the natural history of human cancer. Thus sites of altered DNA methylation constitute promising molecular markers for use in early cancer detection and in monitoring disease progression and treatment responses. ${ }^{29}$ The analysis of serum DNA derived from SCLC patients for caspase-8, Fas and TRAIL-R1 CpG island methylation is a major topic of our current research programes.

Treatment of neuroblastoma cells with either the demethylating drug 5-AzaC or IFN $\gamma$ has been shown in previous studies to induce caspase-8 and Fas expression and to sensitize them to death-receptor-induced death. ${ }^{14,16,17}$ In SCLC cells that are silenced for caspase-8, Fas and TRAIL$\mathrm{R} 1$ expression, treatment with both 5-AzaC and IFN $\gamma$ was necessary to induce sufficient expression of caspase-8, Fas and TRAIL to reduce their resistance to Fas and TRAILinduced death. Unfortunately, the use of demethylating agents such as 5 -AzaC for cancer therapy is limited by toxic side effects; therefore, the development of novel agents that more specifically inhibit the expression of DNA methyltransferases in tumor cells and their use in combination with IFN $\gamma$ and TRAIL is worthwhile. ${ }^{30}$

The identification of strategies used by cancer cells to resist death is of paramount importance for the design of effective therapies. The results of this study demonstrate that the Fas and TRAIL pathways of apoptosis have been effectively inactivated in SCLC cells, which can be partially explained by the simultaneous silencing of caspase-8, Fas and TRAIL-R1 and the intracellular retention of TRAIL-R2. Our laboratory has shown that in SCLC cells the mitochondrial pathway of apoptosis can be effectively activated by antisense-mediated inhibition of $\mathrm{Bcl}-2$ expression. ${ }^{9}$ Further investigations to translate these findings into novel therapeutic concepts that may help to improve the treatment outcome in SCLC are currently underway.

\section{Materials and Methods}

\section{Materials}

Mouse anti-Fas, TRAIL-R1, -R2 and -R3 Mabs and rabbit anti-FLIP antibodies were from Alexis Corporation (Lausen, Switzerland). Mouse anti-caspase-8 Mabs were from Medical and Biological Laboratories (Nagoya, Japan). Mouse anti-caspase-3 Mabs and rabbit anti-caspase-10 antibodies were from Transduction Laboratories and Pharmingen International (Heidelberg, Germany). Rabbit anti-caspase-7 and -9 antibodies were from New England Biolabs (Frankfurt, Germany). 5AzaC sodium bisulfite and hydroquinone were from Sigma (Buchs, Switzerland). Recombinant cross-linked TRAIL was obtained from Alexis Corporation. Supernatants from murine neuroblastoma Neuro2A cells transfected with FasL or empty vector as control were a kind gift of Professor Fontana (University Hospital Zürich, Switzerland). A 1:10 dilution of the Neuro2A supernatant was sufficient to induce death in sensitive cell lines, as previously reported. ${ }^{31}$ Recombinant interferon gamma was purchased from Roche Diagnostics (Mannheim, Germany).

\section{Cell lines}

The Jurkat $\mathrm{T}, \mathrm{H} 460, \mathrm{~N} 417$ and $\mathrm{NCl}-\mathrm{H} 69$ cell lines were obtained from ATCC (Rockville, MD, USA). The SW2, $\mathrm{OH}-1$ and $\mathrm{OH}-3$ cell lines have been described previously. ${ }^{9,32,33}$ Cells were cultured in RPMI/10\% FCS supplemented with $2 \mathrm{mM}$ L-glutamine, $50 \mathrm{IU} / \mathrm{ml}$ penicillin and $50 \mu \mathrm{g} / \mathrm{ml}$ streptomycin. All cell cultures were maintained at $37^{\circ} \mathrm{C}$ in a humidified atmosphere with $5 \% \mathrm{CO}_{2}$.

\section{Tumor material}

Tumor DNA was isolated from $2-5 \mu \mathrm{m}$ paraffin sections as follows. Paraffin-embedded tissue was scraped from three to five slides with a sterile scalpel and paraffin was dissolved in $1 \mathrm{ml}$ xylene. Samples were centrifuged at $12000 \mathrm{rpm}$ for $10 \mathrm{~min}$ and the supernatant discarded. DNA was then precipitated in ethanol, and remaining tissue was digested with $20 \mathrm{mg} / \mathrm{ml}$ proteinase $\mathrm{K}$ at $65^{\circ} \mathrm{C}$, and the enzyme was then inactivated at $95^{\circ} \mathrm{C}$ for $10 \mathrm{~min}$.

\section{Cell growth assays}

Cell viability was quantitated using a colorimetric 3-(4, 5-dimethylthiazol-2yl)-2,5-(3-diphenyl tetrazolium bromide) (MTT) assay (Sigma). Assays were performed on cells plated at 100000 cells/well in 96-well plates. Cells were incubated with ligands at $37^{\circ} \mathrm{C}$ in a humidified $5 \% \mathrm{CO}_{2}$ atmosphere for $16 \mathrm{~h}$, after which $10 \mu \mathrm{l}$ of $10 \mathrm{mg} / \mathrm{ml}$ MTT solution was added to each well, and the cultures incubated for $90 \mathrm{~min}$ at $37^{\circ} \mathrm{C}$, when $100 \mu \mathrm{l}$ MTT lysis buffer was added to stop the reaction. Absorbance was measured with an ELISA plate reader at $570 \mathrm{~nm}$ Trypan blue exclusion assays were performed after plating $10^{6} \mathrm{cells} /$ well in six-well plates. Cells were trypsinized and washed in PBS, then resuspended in 0.4\% trypan blue in PBS. At least 250 living and dead cells were counted per sample using a light microscope and the percentage of dead cells was calculated.

\section{Caspase-3-like activity}

Cells were plated at $10^{6}$ cells/well in six-well plates. After $4 \mathrm{~h}$ incubation with ligand, cells were harvested and washed in PBS, and pellets were resuspended in cell extraction buffer (CEB) $(50 \mu \mathrm{M}$ PIPES, $50 \mu \mathrm{M} \mathrm{KCl}$, $5 \mu \mathrm{M}$ EGTA, $2 \mu \mathrm{M} \mathrm{MgCl}_{2}, 2 \mu \mathrm{M}$ PMSF, $1 \mu \mathrm{M}$ DTT and protease inhibitors). Samples underwent two freeze/thaw cycles and were then centrifuged for $10 \mathrm{~min}$ at $14000 \mathrm{rpm}$ at $4^{\circ} \mathrm{C}$ and the supernatants recovered. A total of $40 \mu \mathrm{g}$ of protein diluted in CEB was pipetted per well of a 96-well plate. Control wells were incubated with $0.01 \mathrm{mM} \mathrm{DEVD-CHO}$ inhibitor (Bachem, Bubendorf, Switzerland), and all wells were incubated with $0.08 \mathrm{mM}$ DEVD-pNa substrate (Bachem) for a minimum of $3 \mathrm{~h}$ at $37^{\circ} \mathrm{C}$. Absorbance was measured at $405 \mathrm{~nm}$ using an ELISA reader. Control values incubated with DEVD-CHO were subtracted from sample values.

\section{RT-PCR}

RNA was isolated from cell lines or tumors using the Rneasy kit according to the manufacturer's instructions (Qiagen, Basel, Switzerland); however tumor samples were initially sonicated in lysis buffer. A total of $1 \mu \mathrm{g}$ of RNA was used to synthesize cDNA, and $10 \%$ of this was used in PCR reactions. Primers and conditions used to amplify Fas, TRAIL-R1, R2, R3 and R4, caspase- 8 and beta actin have been described elsewhere. ${ }^{14}$ One-fifth of PCR product was loaded on $2 \%$ agarose gels and visualized with ethidium bromide. Amplification of genomic DNA was controlled by omitting reverse transcriptase from the cDNA synthesis reaction. 


\section{Flow cytometry}

For FACs staining of intact cells, cells were washed in FACs buffer (1\% BSA in PBS) and incubated with $1 \mu \mathrm{g} / \mathrm{ml}$ FITC-conjugated anti-human Fas Mab and $10 \mu \mathrm{g} / \mathrm{ml}$ TRAIL-R1, and -R2 Mabs on ice. Cells stained for TRAIL receptors were then incubated with $5 \mu \mathrm{g} / \mathrm{ml}$ FITC-conjugated antimouse IgG1 antibodies (BD Pharmingen). Cells were washed and fixed in $4 \%$ paraformaldehyde in PBS. For intracellular FACs staining, cells were initially fixed in $4 \%$ paraformaldehyde in PBS and permeabilized with $0.1 \%$ saponin in PBS prior to FACs staining. Isotype matched Mabs from Pharmingen were used as controls. Approximately 10000 events were collected using a Becton Dickinson FACS-calibur machine.

\section{Western blotting}

Cells were resuspended in lysis buffer ( $1 \%$ NP-40, $0.1 \%$ SDS, $0.5 \%$ sodium deoxycholate, $150 \mathrm{mM} \mathrm{NaCl}, 20 \mathrm{mM}$ Tris- $\mathrm{HCl}$ pH 8, $1 \mu \mathrm{M}$ PMSF, and protease inhibitors). A total of $100 \mu \mathrm{g}$ of protein was separated by $12 \%$ SDS-PAGE and transferred onto PVDF membranes. Blots were blocked with $5 \%$ milk in TBS $+0.05 \%$ Tween20 (TBST) and incubated overnight at $4{ }^{\circ} \mathrm{C}$ with primary antibodies. Blots were then washed in TBST and incubated for $1 \mathrm{~h}$ with secondary polyclonal antibodies coupled to horseradish peroxidase. Blots were then washed in TBST and developed using ECL chemiluminesence (Amersham Pharmacia Biotech Europe $\mathrm{GmbH}$, Dübendorf, Switzerland).

\section{MSP}

DNA was isolated from cell lines or tumors using Qiagen Dneasy kit according to the manufacturer's instructions. Bisulfite modification of DNA was performed as described elsewhere. ${ }^{34}$ PCR reactions were performed using $100 \mathrm{ng}$ bisulphate-modified DNA as template and using FastStartTaq polymerase (Roche Molecular Biochemicals, Rotkreuz, Switzerland). Amplification of unmodified genomic DNA was controlled by omitting the bisulfite treatment. One-fifth of PCR products were loaded on $6 \%$ polyacrylamide gels. The sequences of primers used are shown in Table 2. Caspase- 8 primers are described by Teitz et al. ${ }^{27}$ while the other primers were designed using the Gene Runner Software program. The following PCR conditions were used: for caspase-8 PCR reactions, the annealing temperature was $55^{\circ} \mathrm{C}$ and the number of cycles was 40 ; for TRAIL-R1, the annealing temperature was $60^{\circ} \mathrm{C}$ and the cycle number was 40; and for Fas, the annealing temperature was $57^{\circ} \mathrm{C}$ and the cycle number was 35 . Samples that gave positive methylation products were also analyzed by restriction enzyme digestion of the resulting PCR product. The endonuclease Taql cuts once at (T/CGA) in the amplified regions of the methylated Fas, TRAIL-R1 and caspase- 8 CpG islands, but not the corresponding unmethylated $\mathrm{CpG}$ islands. It was therefore used to verify the methylation status samples (data not shown).

\section{Acknowledgments}

We thank Drs. Michael Grotzer and Dirk Steinhoff (KinderSpital Zürich, Switzerland) for advice regarding the MSP technique. This work was funded by the Swiss Cancer League.

\section{References}

1. Greenlee RT, Murray T, Bolden S and Wingo PA (2000) Cancer statistics, 2000. CA Cancer J. Clin. 50: 7-33.
2. Wistuba II, Gazdar AF and Minna JD (2001) Molecular genetics of small cell lung carcinoma. Semin. Oncol. 28: 3-13.

3. Prins J, De Vries EG and Mulder NH (1993) The myc family of oncogenes and their presence and importance in small-cell lung carcinoma and other tumour types. Anticancer Res. 13: 1373-1385

4. Brodeur GM Seeger RC Schwab M Varmus HE and Bishop JM (1984) Amplification of $\mathrm{N}$-myc in untreated human neuroblastomas correlates with advanced disease stage. Science 224: 1121-1124

5. Kaufmann SH and Earnshaw WC (2000) Induction of apoptosis by cancer chemotherapy. Exp. Cell Res. 256: 42-49

6. Daniel PT, Wieder T, Sturm I and Schulze-Osthoff K (2001) The kiss of death: promises and failures of death receptors and ligands in cancer therapy. Leukemia 15: 1022-1032.

7. Scaffidi C, Fulda S, Srinivasan A, Friesen C, Li F, Tomaselli KJ, Debatin KM, Krammer PH and Peter ME (1998) Two CD95 (APO-1/Fas) signaling pathways. EMBO J. 17: 1675-1687

8. Jiang SX, Sato Y, Kuwao S and Kameya T (1995) Expression of bcl-2 oncogene protein is prevalent in small cell lung carcinomas. J. Pathol. 177: 135-138

9. Ziegler A, Luedke GH, Fabbro D, Altmann KH and Zangemeister-Wittke $U$ (1997) Induction of apoptosis in small-cell lung cancer cells by an antisense oligodeoxynucleotide targeting the Bcl-2 coding sequence. J. Natl. Cancer Inst. 89: $1027-1036$

10. Fisher MJ, Virmani AK, Wu L, Aplenc R, Harper JC, Powell SM, Rebbeck TR, Sidransky D, Gazdar AF and El Deiry WS (2001) Nucleotide substitution in the ectodomain of trail receptor $\mathrm{dr} 4$ is associated with lung cancer and head and neck cancer. Clin. Cancer Res. 7: 1688-1697

11. Joseph B, Ekedahl J, Sirzen F, Lewensohn R and Zhivotovsky B (1999) Differences in expression of pro-caspases in small cell and non-small cell lung carcinoma. Biochem. Biophys. Res. Commun. 262: 381-387

12. Zhang XD, Franco AV, Nguyen T, Gray CP and Hersey P (2000) Differential localization and regulation of death and decoy receptors for TNF-related apoptosis-inducing ligand (TRAIL) in human melanoma cells. J. Immunol. 164: 3961-3970

13. Sirzen F, Zhivotovsky B, Nilsson A, Bergh J and Lewensohn R (1998) Higher spontaneous apoptotic index in small cell compared with non-small cell lung carcinoma cell lines; lack of correlation with Bcl-2/Bax. Lung Cancer 22: 1-13

14. Hopkins-Donaldson S, Bodmer JL, Bourloud KB, Brognara CB, Tschopp J and Gross N (2000) Loss of caspase-8 expression in highly malignant human neuroblastoma cells correlates with resistance to tumor necrosis factor-related apoptosis-inducing ligand-induced apoptosis. Cancer Res. 60: 4315-4319

15. Peli J, Schroter M, Rudaz C, Hahne M, Meyer C, Reichmann E and Tschopp J (1999) Oncogenic Ras inhibits Fas ligand-mediated apoptosis by downregulating the expression of Fas. EMBO J. 18: 1824-1831

16. Fulda $S$ and Debatin KM (2002) IFNgamma sensitizes for apoptosis by upregulating caspase-8 expression through the Stat1 pathway. Oncogene 21: 2295-2308

17. Bernassola F, Scheuerpflug C, Herr I, Krammer PH, Debatin KM and Melino G (1999) Induction of apoptosis by IFNgamma in human neuroblastoma cell lines through the CD95/CD95L autocrine circuit. Cell Death Differ. 6: 652-660

18. Lee SH, Shin MS, Kim HS, Lee HK, Park WS, Kim SY, Lee JH, Han SY, Park JY, Oh RR, Kang CS, Kim KM, Jang JJ, Nam SW, Lee JY and Yoo NJ (2001) Somatic mutations of TRAIL-receptor 1 and TRAIL-receptor 2 genes in nonHodgkin's lymphoma. Oncogene 20: 399-403

19. Natoli G, lanni A, Costanzo A, De Petrillo G, llari I, Chirillo $P$, Balsano $C$ and Levrero M (1995) Resistance to Fas-mediated apoptosis in human hepatoma cells. Oncogene 11: 1157-1164

20. Ibrahim SM, Ringel J, Schmidt C, Ringel B, Muller P, Koczan D, Thiesen HJ and Lohr M (2001) Pancreatic adenocarcinoma cell lines show variable susceptibility to TRAIL-mediated cell death. Pancreas 23: 72-79

21. Irmler M, Thome M, Hahne M, Schneider P, Hofmann K, Steiner V, Bodmer JL, Schroter M, Burns K, Mattmann C, Rimoldi D, French LE and Tschopp J (1997) Inhibition of death receptor signals by cellular FLIP. Nature 388: 190-195

22. Grotzer MA, Eggert A, Zuzak TJ, Janss AJ, Marwaha S, Wiewrodt BR, Ikegaki $\mathrm{N}$, Brodeur GM and Phillips PC (2000) Resistance to TRAlL-induced apoptosis in primitive neuroectodermal brain tumor cells correlates with a loss of caspase8 expression. Oncogene 19: 4604-4610

23. Santourlidis S, Warskulat U, Florl AR, Maas S, Pulte T, Fischer J, Muller W and Schulz WA (2001) Hypermethylation of the tumor necrosis factor receptor 
superfamily 6 (APT1, Fas, CD95/Apo-1) gene promoter at rel/nuclear factor kappaB sites in prostatic carcinoma. Mol. Carcinog. 32: 36-43

24. Wu WG, Soria JC, Wang L, Kemp BL and Mao L (2000) TRAlL-R2 is not correlated with $\mathrm{p} 53$ status and is rarely mutated in non-small cell lung cancer. Anticancer Res. 20: 4525-4529

25. Kataoka T, Budd RC, Holler N, Thome M, Martinon F, Irmler M, Burns K, Hahne M, Kennedy N, Kovacsovics M and Tschopp J (2000) The caspase-8 inhibitor FLIP promotes activation of NF-kappaB and Erk signaling pathways. Curr. Biol. 10: $640-648$

26. Esteller M, Corn PG, Baylin SB and Herman JG (2001) A gene hypermethylation profile of human cancer. Cancer Res. 61: 3225-3229

27. Teitz T, Wei T, Valentine MB, Vanin EF, Grenet J, Valentine VA, Behm f, Look AT, Lahti JM and Kidd VJ (2000) Caspase 8 is deleted or silenced preferentially in childhood neuroblastomas with amplification of MYCN. Nat. Med. 6: 529-535

28. Beltinger C, Bohler T, Karawajew L, Ludwig WD, Schrappe M and Debatin KM (1998) Mutation analysis of CD95 (APO-1/Fas) in childhood B-lineage acute lymphoblastic leukaemia. Br. J. Haematol. 102: 722-728
29. Esteller M, Sanchez-Cespedes M, Rosell R, Sidransky D, Baylin SB and Herman JG (1999) Detection of aberrant promoter hypermethylation of tumor suppressor genes in serum DNA from non-small cell lung cancer patients. Cancer Res. 59: 67-70

30. MacLeod AR and Szyf M (1995) Expression of antisense to DNA methyltransferase mRNA induces DNA demethylation and inhibits tumorigenesis. J. Biol. Chem. 270: 8037-8043

31. Shimizu M, Fontana A, Takeda Y, Yagita H, Yoshimoto T and Matsuzawa A (1999) Induction of antitumor immunity with Fas/APO-1 ligand (CD95L)transfected neuroblastoma neuro-2a cells. J. Immunol. 162: 7350-7357

32. Goodwin G and Baylin SB (1982) Relationships between neuroendocrine differentiation and sensitivity to gamma-radiation in culture line $\mathrm{OH}-1$ of human small cell lung carcinoma. Cancer Res. 42: 1361-1367

33. Kaufmann SH, Mabry M, Jasti R and Shaper JH (1991) Differential expression of nuclear envelope lamins $A$ and $C$ in human lung cancer cell lines. Cancer Res. 51: $581-586$

34. Herman JG, Graff JR, Myohanen S, Nelkin BD and Baylin SB (1996) Methylation-specific PCR: a novel PCR assay for methylation status of $\mathrm{CpG}$ islands. Proc. Natl. Acad. Sci. USA 93: 9821-9826 